\title{
Unearthing The Most Vulnerable: Psychological Impact of Natural Disasters
}

Received 2 July 2006

Revised 12 January 2007

Accepted 24 January 2007

Natural calamities, such as earthquakes, hurricanes, cyclones and floods are some of the traumatic disasters that may cause posttraumatic stress disorder ${ }^{1}$. Natural disasters can be severe, cause mass destruction, and affect millions of people, placing a strain on the mental health. In post-trauma scenario, raised degrees of stress could lead to depression and other mental illnesses especially among those who have lost their loved ones and livelihood ${ }^{2}$. The breakdown of traditional community structures, the loss of familysupport systems, long-distance immigration and economic uncertainty all take their toll, in the form of a rise in mental disorders. Research shows that people who lose family members suffer from significant severe psychological distress compared to those who do not. Women have been seen to be the most suffering victims in this regard $^{3}$. People exposed to such events are far more likely to develop psychiatric disorders such as substance abuse, major depression and psycho-

\author{
M. Shafique Sajid, MBBS, MBA, FRCS* \\ * Department of Vascular Surgery, Royal Free \\ Hospital, Pond Street, Hampstead, London \\ NW3 2QG \\ UNITED KINGDOM
}

somatic illnesses which can present as an isolated disorder or as a part of post traumatic stress disorder (PTSD) ${ }^{4}$. Rescue workers and medical teams are also equally prone to develop nay kind of mental, psychological and psychosomatic disorders 5 . After atrocious disasters of South Asian Tsunami, earthquake in Pakistan and hurricane Katrina in New Orleans, it is obvious that health care services and structures with any amount of funds and human resources would face formidable difficulty in coping with thousands of traumatized people seeking cure and care. The unprecedented tragedy killed thousands causing an immense emotional and psychological trauma for scores of people who have survived. The unpreparedness for natural disasters has been compounded with extremely inaccessible geographical location of affected areas, poor planning, insufficient machinery and equipment. This causes delay in rescue and relief operations and further aggravate the psychological consequences of 
earthquakes. Those physically injured are treated and those who will suffer from epidemics will be cured in due course of time. However, besides mobile and field hospitals, this situation necessitates establishing social support and counselling centres in all the affected areas for treating patients with psychiatric morbidities. Among survivors who are at increased risk for developing posttraumatic sequelae, women are undoubtedly more vulnerable to suffer from depression, anxiety, post-traumatic stress and impaired well-being. Children presenting depressive symptoms also need substantial psychological support and counselling to cope with the event. Other group is of the rescue workers and the volunteers who are being exposed to mutilated bodies, mass destruction, and lifethreatening situations and may become unseen victims ${ }^{5}$. In many cases, their experiences may induce various psychological disorders. In this state of affairs, an army of public health professionals, psychologists, counsellors, community and rural development specialists, social workers, legal advisors should be called upon immediately. The screening of all such vulnerable cases ought to be an active element in the strategies being designed for the urgent treatment and long term rehabilitation of all the affected areas. To embark upon this new burden of disease, government, non-governmental organizations, international donors and civil society organizations must jointly take steps to ensure timely and effective delivery of outreach mental health services to all the survived victims in this time of acute need.

\section{References}

1. American Psychiatric Association. Diagnostic and statistical manual of mental disorders. 4th ed. Washington DC: 1994.

2. Ben-Ezra M, Essar N. Depression and anxiety in developing countries. Lancet 2004; 364: 1488.

3. Montazeri A, Baradevan H, Omidvari S, Azin SA, Ebadi M, Goramaroudi G. Psychological distress among Bam earthquake survivors in Iran: a population-based study. BMC Public Health 2005; 5: 4.

4. Tural U, Coskun B, Onder E, Corapaoglu A, Yildiz M, Kesepara C. Psychological consequences of the 1999 earthquake in Turkey. J Trauma Stress 2004; 17: 451-9.

5. Guo YJ, Chen CH, Lu ML, Tan HK, Lee HW, Wang TN. Posttraumatic stress disorder among professional and non-professional rescuers involved in an earthquake in Taiwan. Psychiatry Res 2004; 127: 35-41.

Address for correspondence:

Mr MS Sajid

Surgical Research Fellow

Washington Suite, North Wing, Worthing Hospital, West

Sussex. BN11 2DH. UK

Phone: 01903205111 ext. 4030

Mobile: 07717852412

Fax: 01903285052

E-mail: surgeon1wrh@hotmail.com 